\title{
Monitoring of Erosion Preventive Structures Based on Eco-Engineering Approaches: The Case of the Mixed Check Dams of Masonry and Forest Residues
}

\author{
Guillermo Tardio Cerrillo ${ }^{1 *}$ and Jose Luis Garcia Rodriguez ${ }^{2}$ \\ ${ }^{1}$ Forestry engineer. Avenida Niceto Alcalá Zamora, 6, 4 D. 28905. Getafe (Madrid). Spain. \\ ${ }^{2}$ Technical University of Madrid. Ciudad Universitaria s/n. 28040 Madrid. Spain
}

Received 2 April 2016; Accepted 10 May 2016

\begin{abstract}
The mixed check dams were conceived in late 2007, during actions to control the onset of erosion processes in Teide National Park subsequent to a forest fire. A simplified scheme of these mixed check dams consists of a structure of horizontal and vertical wooden elements creating a core that is filled with fine branches and forest residues. Besides this, rocks are placed on both sides of the check dam. The mixed check dam technique follows an eco-engineering design approach. These check dams are temporary structures because their cores will decompose in a few years (from 5-10 years depending on the size of the forest residues used). After our last visit to Tenerife (August 2012), it could be checked that the mixed check dams are providing the predicted results. The sedimentation processes achieved are satisfactory. Based on the collected data during the monitoring stage, the performance of this technique can be already characterised successful.
\end{abstract}

Keywords: Forest fire, erosion control, eco-engineering, Tenerife.

\section{Introduction}

Eco-engineering is the use of living plants or cut plant material, either alone or in combination with inert structures, to control soil erosion and the mass movement of land in order to fulfil engineering functions [1]. The self-repairing characteristics of the vegetation used, and the resilience capacity of the bioengineered area [2] are very important allies in the eco-engineering design philosophy.

The eco-engineering philosophy follows the sustainability idea by using readily available material on or adjacent to the site such as wood or rocks. The use of wood material that originates from nearby silvicultural treatments [3] can lead to utilizing material with a wide variety of properties from different species.

The eco-engineering solutions have inherent advantages over classic civil engineering solutions with respect to economy, ease of construction, low landscape impact and opportunities for incorporation of vegetation or plantings within the structure [4]. In contrast, one of the main design disadvantages are related to this latter issue since the use of both living and inert biological materials (e.g. wood) involves incorporating temporary variable elements in terms of design and performance reliability of the eco-engineering works [5]. Because of this, a monitoring stage is essential in order to collect data and check the performance of the ecoengineering intervention as time progresses.

There are three different approaches regarding the way the living material (the plants) play a stabilizing role in this kind of interventions. One approach consists in establishing

\footnotetext{
*E-mail address: gtarcer@gmail.com

ISSN: 1791-2377 @ 2016 Eastern Macedonia and Thrace Institute of Technology. All rights reserved.
}

the plants during the construction stage. In another approach there are no plantation works initially, the inert material plays the initial stabilising role and the indigenous plants colonise the area as time progresses. After several years the main stabilising factor will be represented by the indigenous plant species. Finally, a third possibility consists of a combination of the two preceding approaches.

Another important feature of the eco-engineering design approach is the use of the material readily available in the area. Therefore, whenever possible, the wooden structures will be constructed by using the logs present in the surroundings of the construction site. Finally, the use of non treated wood in this type of structures involves that the wooden elements will degrade with time and, because of an inevitable stress transfer process, the logs will transfer their stabilising effect to the evolving indigenous plants that are colonising the stabilised soil.

During 30 and 31 July and 1 and 2 August 2007, the Canarian towns of Los Realejos, San Juan de la Rambla, La Guancha, Icod, Garachico, Los Silos, Buenavista del Norte, El Tanque, Santiago del Teide and Guía de Isora were affected by a huge forest fire that burned down a remarkable part of a Pinus canariensis forest. The total surface burned was over 18,000 ha.

The mixed check dam technique was conceived and designed by Guillermo Tardío in late 2007, during actions to protect and preserve the soil in Teide National Park. On one hand, the wood used in the structures came from the silvicultural treatments that were taking place after the forest fire. In this case, the inert elements fulfilled the initial stabilising needs and, as time progresses, the indigenous species colonised the area while the wooden elements progressively decayed.

Before the use of the mixed check dams there were no previous experiences with eco-engineering techniques in the 
Tenerife Island. The performance of these structures has triggered a change of the Tenerife local Administration attitude regarding the use of eco-engineering approaches in their interventions.

A visual monitoring plan was followed in order to check the eco-engineering structure evolution and its performance in terms of soil conservation and landscape restoration. The main aim of this article is showing the particularities of the mixed check dam technique from both a design stage and a visual monitoring stage.

\section{Study area}

The study area is near San Juan de la Rambla which is a municipality of Tenerife Island. It is located in a forested area dominated by Pinus canariensis and Myrica faya. The topography is very steep and gullies are very common in the area.

A forest trail were mixed check dams were constructed was selected. This trail is known as "Caño Chinque-La Tahona). The UTM coordinates of the beginning of this forest trail are 28R X:339977, Y: 3137250. A location of the mixed check dams is shown in Fig.1.

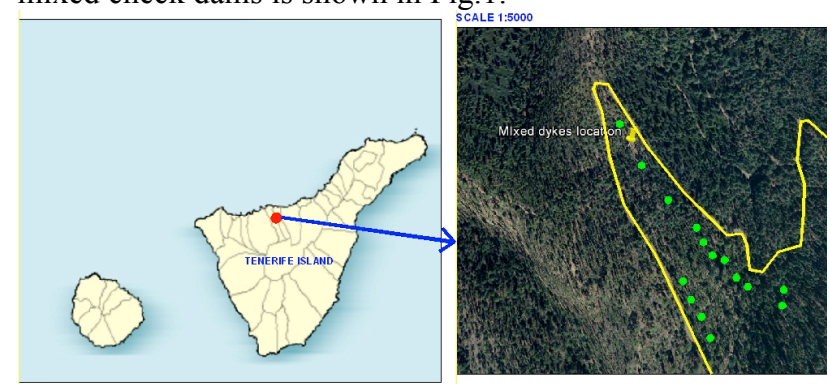

Fig. 1. Monitored mixed check dams location are represented as green circles (right figure with 1:5000 drawing scale).

\section{Mixed check dam description}

As shown in Fig.2, a simplified scheme of these mixed check dams consists of a structure of horizontal and vertical elements creating a core that is filled with fine branches and forest residues. Besides this, rocks are placed on both sides of the check dam. The vertical elements are tied to each other by means of a biodegradable rope and the end points of the check dam are anchored to the ground or to any adjacent tree, bush or stumps.
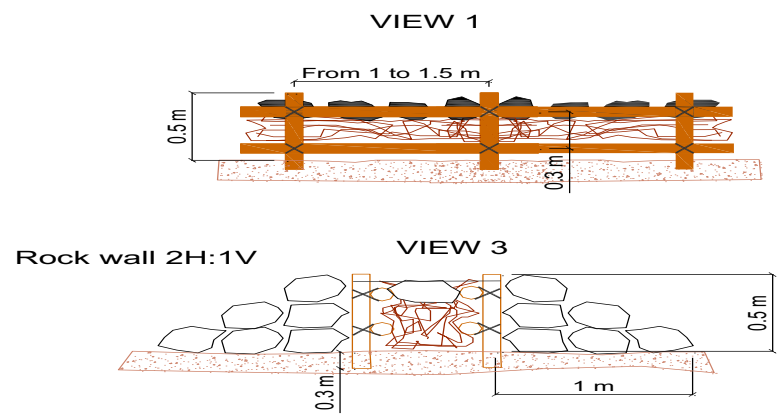

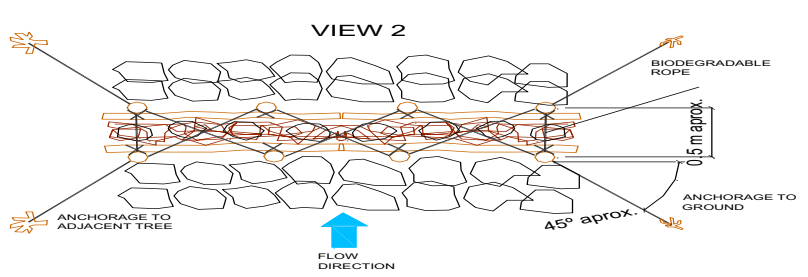

Fig. 2. Mixed check dam profile (view 1), cross sectional view (view 3) and plan view (view 2) (drawings elaborated by Guillermo Tardío).

One of the main features in the mixed check dam design was the use of the abundant forest biomass $[6,7]$ generated during the cuttings that were conducted. So far, the biggest size check dam built was $2.5 \mathrm{~m}$ high and $15 \mathrm{~m}$ wide. The main elements of a mixed check dam are shown in Fig.3.

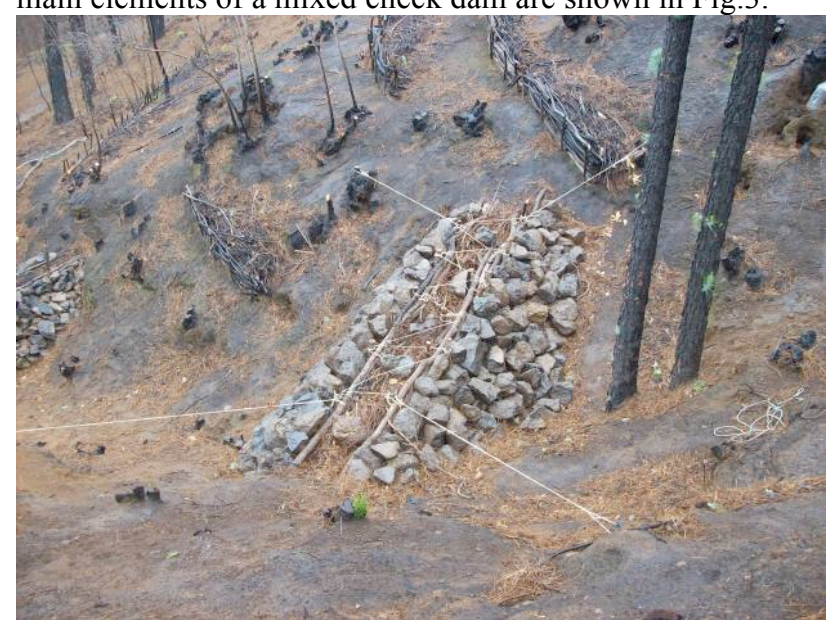

A)

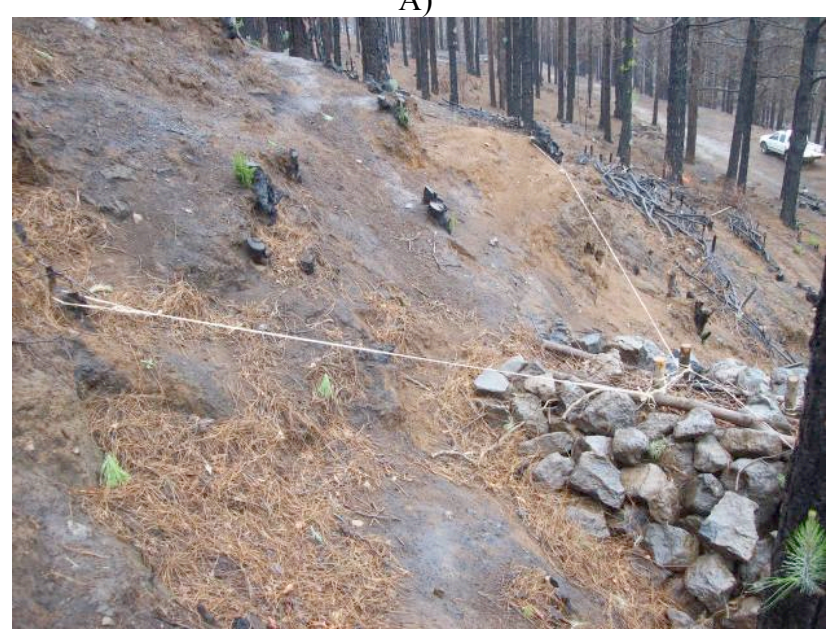

B)

Fig. 3. A) Mixed check dam completely built. B) Detail of the anchoring of a mixed check dam to the ground (photographs taken by Guillermo Tardío).

Distances between the cross barriers (see Fig.4) depend on both the height of the check dam and the slope of the gully [8]. All the materials used in its construction are biodegradable, allowing for the creation of a new and fertilized substrate that will, as time progresses, be colonized by indigenous species. 

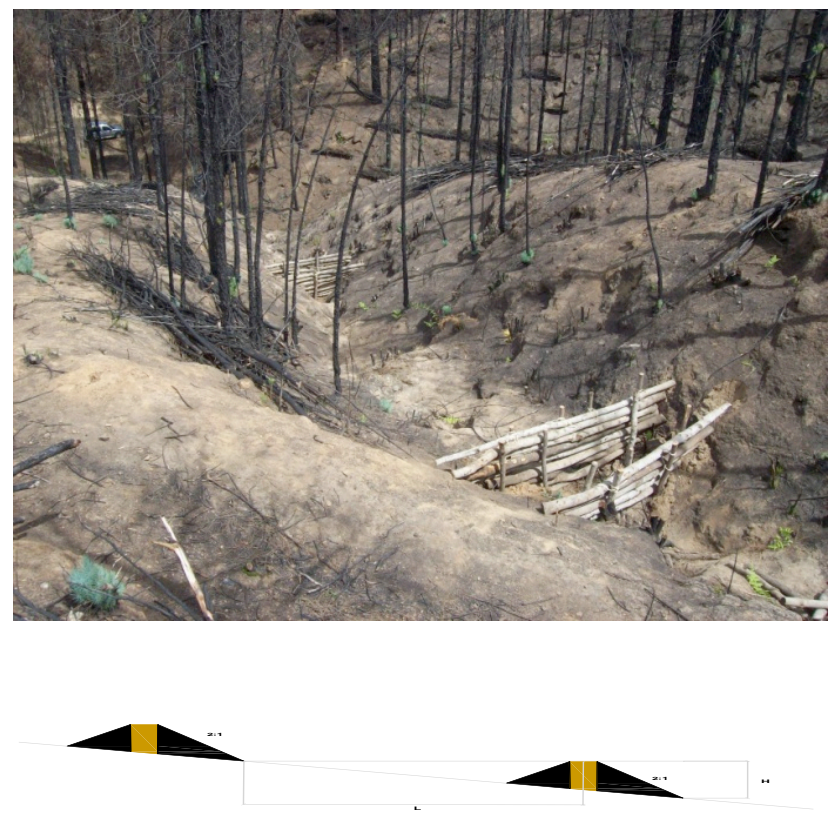

Fig. 4. The series of mixed check dams will decrease the general slope within the gullies (drawing elaborated by the authors and photograph taken by Carlos Caballero).

This technique follows the ecological engineering philosophy because:

- The matrix formed by the fine residues creates a fertilized substrate that, as time progresses, is colonized by indigenous species. As time pass, the existing voids within the core of the check dam are filled with the materials carried by the runoff.

- All the materials used in its construction are biodegradable and the stabilised soil will be colonized by the indigenous species. Besides, the body of the check dam is permeable and, because of this, water flows through its body but in a controlled way.

- As time progresses, the effect of the mixed check dams inert elements will be replaced by the effects of the colonizing vegetation. Eventually, the mixed check dams will be decomposed and will disappear and the anchoring function to the ground will be played by the vegetation. The sediment mounds caused by the check dams will turn into a series of green islands throughout the gullies.

\section{Dimensions of the vertical and horizontal elements}

The calculation scheme at the design stage was as follows: once the height of the water level is determined in a certain cross section where a mixed check dam will de located [9, $10,11]$, the next step is the calculation of the minimum diameter necessary to resist the forces involved. These forces are both water pressure and the rock walls that the check dam has on both sides. All the elements are calculated according to wood structure calculation principles [12].

As shown in Fig.5, both the vertical and the horizontal elements were calculated as a two pin support beam. The limit state condition in the internal stability check allowed the minimum diameter calculation for both type of elements. The horizontal elements were designed as beams subjected to a uniform pressure (Fig.5A) while the vertical elements were designed as beams subjected to pressures following a triangular distribution shape (Fig.5B).

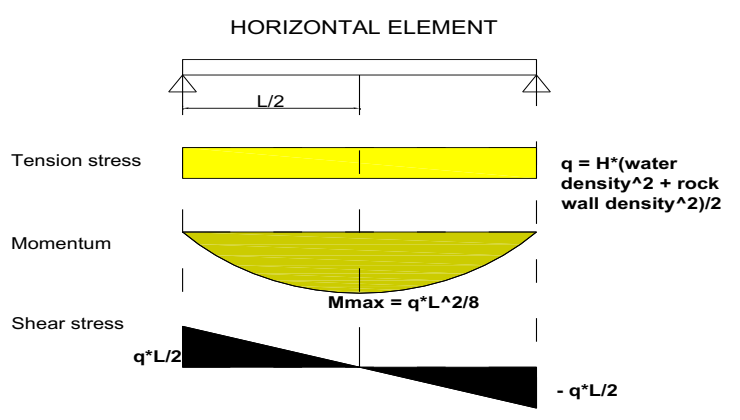

A)

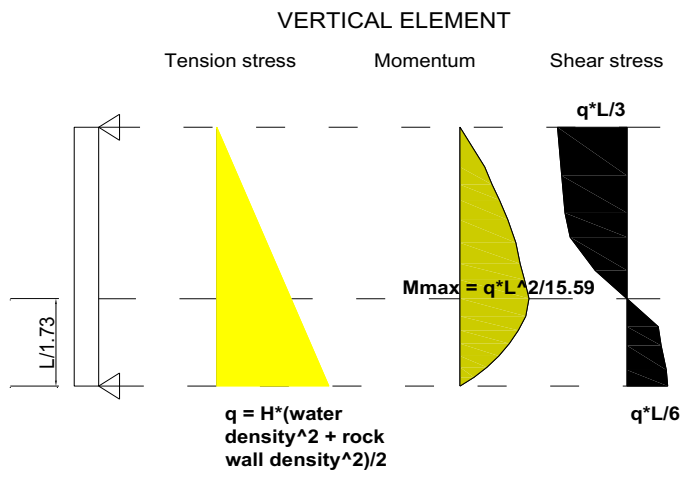

B)

Fig. 5. Tension and shear stress diagrams. $\mathrm{q}$ is the total pressure exerted on the wooden element (drawings elaborated by the authors). A) Horizontal wooden elements, B) Vertical wooden elements.

In order to calculate the necessary dimension of the circular cross sections, the maximum stress to be resisted by the wooden elements was calculated according to Eq. 1 and Eq.2:

$$
\sigma_{\max }=M_{\max } / W
$$

and

$$
X_{d}=K_{\mathrm{mod}} K_{k} / \gamma_{m}
$$

Where:

$\sigma_{\max }=$ maximum normal stress, $M_{\max }=$ maximum bending moment, $\mathrm{W}=$ bending stiffness for a circular cross section case, $X_{d}=$ wooden element design strength, $K_{\text {mod }}$ =modification factor (with this factor the moisture content effects and the load duration effects are included in the calculation), $\mathrm{K}_{\mathrm{k}}=$ wooden element characteristic strength, $\gamma_{\mathrm{m}}=$ material partial safety factor.

As shown in Fig.5, to determine the maximum bending point both the rock wall pressure and the runoff water pressure were considered. The water level within the gully was calculated assuming a runoff corresponding to a $100 \mathrm{yr}$ return period rainfall event. The values of the variables used in the calculations are shown in Tab.1.

Table 1. Values used in the wooden elements design. 


\begin{tabular}{ccccc}
\hline $\mathbf{K}_{\text {mod }}$ & $\boldsymbol{\gamma}_{\mathbf{m}}$ & $\mathbf{K}_{\mathbf{k}}$ & $\begin{array}{c}\text { Runoff } \\
\text { water } \\
\text { density }\end{array}$ & $\begin{array}{c}\text { Rock } \\
\text { wall } \\
\text { density }\end{array}$ \\
\hline 0.7 & 1.3 & $\begin{array}{c}10 \\
\mathrm{~N} / \mathrm{mm}^{2}\end{array}$ & $1.2 \mathrm{t} / \mathrm{m}^{3}$ & $1.8 \mathrm{t} / \mathrm{m}^{3}$ \\
\hline
\end{tabular}

Although it was not assessed, another important characteristic to be taken into account is the permeable nature of these structures. The first point to consider would be the assessment of the flow through its body. In this case, due to both the size of the porous medium and the runoff speed, the flow through the check dam is turbulent. The permeable nature of these check dams allows a controlled evacuation of the runoff through the check dam. This includes the control of runoff speed and the subsequent lowering of water erosion capacity.

\section{Results}

By following the preceding calculation scheme, the minimum diameters of both the vertical and the horizontal elements are shown in the Tab.2 and Tab.3.

Table 2. Minimum diameter of the vertical elements for different check dam heights.

\begin{tabular}{c|c}
\hline $\begin{array}{c}\text { Minimum diameter for the } \\
\text { vertical elements }(\mathbf{c m})\end{array}$ & $\begin{array}{c}\text { Height of the check dam } \\
(\mathbf{m})\end{array}$ \\
\hline 5.8 & 1.0 \\
6.3 & 1.5 \\
7.0 & 2.0 \\
\hline
\end{tabular}

Table 3. Minimum diameter of the horizontal elements for different check dam heights.

\begin{tabular}{c|c|c}
\hline $\begin{array}{c}\text { Minimum } \\
\text { diameter of the } \\
\text { horizontal } \\
\text { element }(\mathbf{c m})\end{array}$ & $\begin{array}{c}\text { Width of the check } \\
\text { dam's core }(\mathbf{m})\end{array}$ & $\begin{array}{c}\text { Height of the } \\
\text { check dam (m) }\end{array}$ \\
\hline 7.2 & 0.5 & 1.0 \\
7.8 & 0.5 & 1.5 \\
8.6 & 0.5 & 2.0 \\
\hline
\end{tabular}

Despite the lack of data regarding the sedimentation rates, after our visits to the study site, we confirmed that these structures are performing well. In Fig.6 the first colonisation stages by the surrounding indigenous vegetation of the check dams sedimentation mounds can be observed.

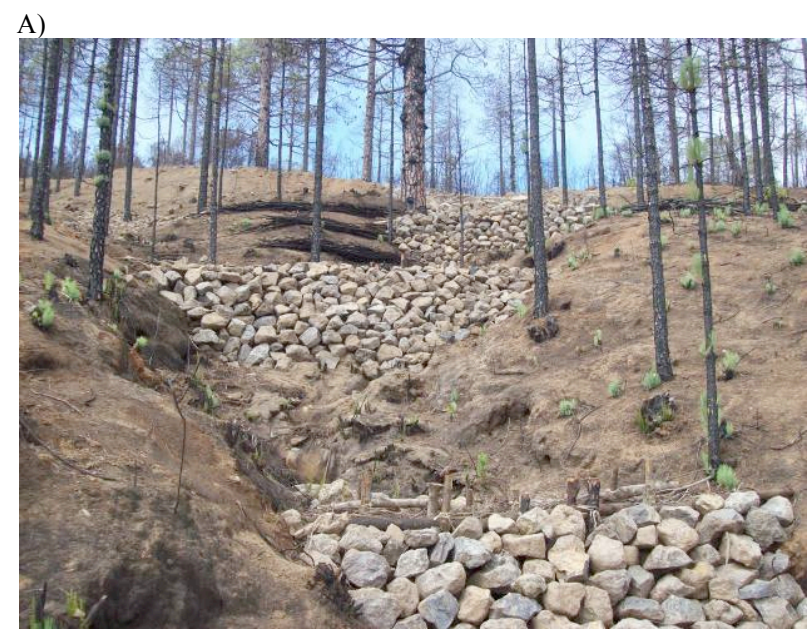

B)

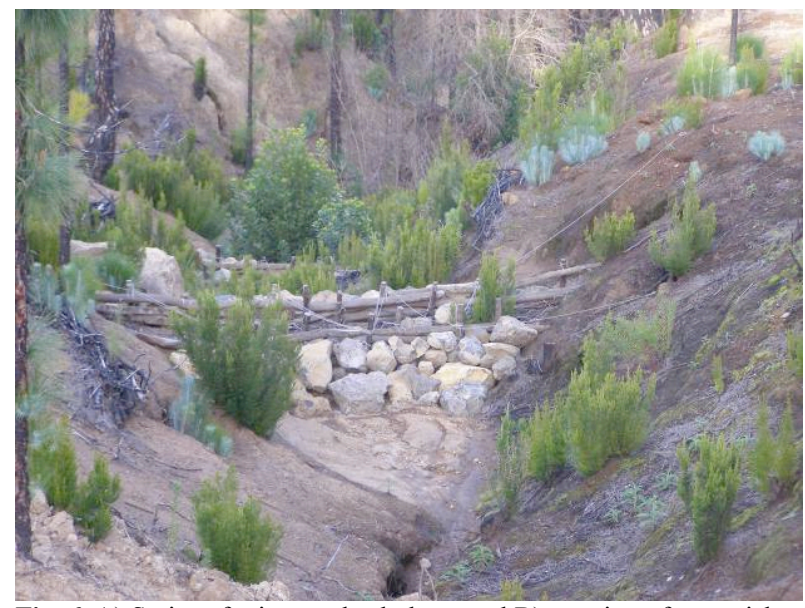

Fig. 6. A) Series of mixture check dams and B) creation of green islands throughout the gully. As it can be observed, the very core of the check dam was colonized by indigenous species. (Photographs taken by Guillermo Tardío).

Results based on the monitoring: the site was visited during 2008-2012 and the mixed check dam performance was checked. The wooden elements of smaller check dams were decomposed fulfilling their condition as temporary structures. Most of the check dams had formed stable sedimentation mounds allowing the indigenous plants to colonise the soil within the gullies.

Plant densities were higher in the gully compared to the surrounding areas (see Fig. 7A). In all cases, there is a clear transitional evolution from the initial structures to the local natural Canarian landscape since the different species are taking the stabilisation function over (see Fig.7).

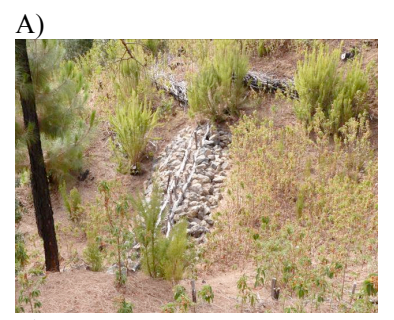

C)

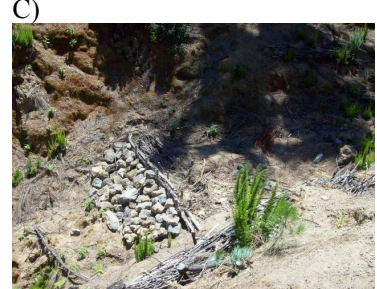

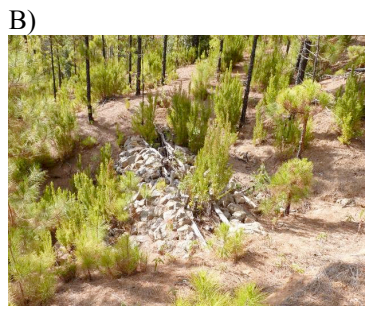

D)

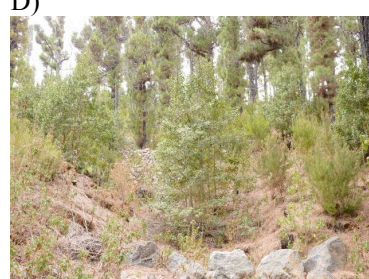

Fig. 7. A) Plant density is higher in the sedimentation mounds, B) indigenous species are taking over the stabilisation effects, C) small mixed check dam with its wooden elements in a clear decaying process and D) a series of mixed check dams is being replaced by the local natural landscape (Photographs taken by Carlos Caballero).

\section{Discussion and Conclusion}

The use of forest residues for erosion control works is a very useful strategy in forest management. As shown in Fig.8, the size of the minimum diameters needed to create a stable mixed check dam could be obtained in almost every forestry treatment (for instance, using cuttings, thinning and tree prunings products). The permeable nature of this type of check dam permits the evacuation of runoff flow in a controlled way. 

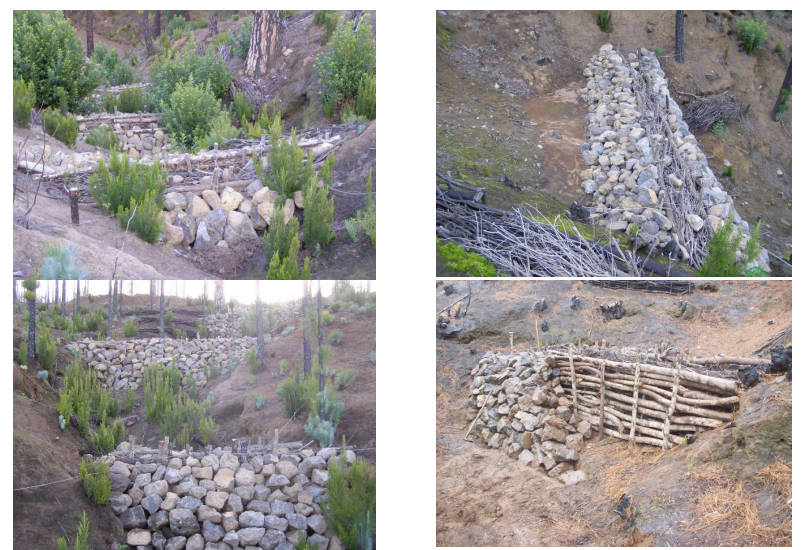

Fig. 8. Pictures of the mixed check dams evolution, effects and main elements of the design. (Photographs taken by Guillermo Tardío).

The resistance transfer between the inert material and the plants was successfully accomplished. The wooden elements were fully decayed by the time the plants had already colonized the gullies.

The direct and indirect benefits of the use of this erosion control technique were acknowledged by both the Local and National Administrations. Indeed, this technique was included in the Spanish National list of techniques to fight against desertification processes.

After a five year visual monitoring plan, the following conclusions were reached:

The design calculations were right.

The sedimentation mounds caused by the check dams were turned into a series of green islands throughout the gullies.

The very cores of the mixed check dams were colonized by indigenous species.

This technique was effective at re-vegetating areas with erosion control problems.
The eco-engineering philosophy was fulfilled if the following terms:

The use of the woody material of the nearby areas was effective.

The utilized inert material (logs and rocks) effectively performed their initial necessary stabilizing role. Afterwards the indigenous species colonized the stabilized soil within the gullies.

The use of forestry residues for erosion control techniques is a very recommendable strategy in forestry management.

As with any stabilization technique, there is a stress (or load) transfer between the soil and the structure but, in contrast to other solutions, this initial response is substituted by an evolving role of the living material used in the ecoengineering structure as time progresses.

The decreasing slope within the gullies as well as the presence of stabilised sedimentation mounds allowed the indigenous species to colonise the area and, as time progressed, to perform the stabilising function by themselves. From this stage on, the very dynamic nature of vegetation will continuously increase the overall resilience of the ecosystem.

This paper was presented at International Conference titled "Frontiers in Environmental and Water Management", that took place March 19-21st 2015, at Kavala Greece.

\section{Acknowledgments}

We would like to thank Mr. Carlos Caballero Serrano for his invaluable help during the field and monitoring work. We also like to thank the reviewers for their corrections and suggestions. Undoubtedly, they improved the final version of this article.
1. H.M.Schiechtl, Hangsicherungen mit ingenieurbiologischen Methoden im Alpenraum. Erosionbeckämpfung im Hochgebirge. Jahrb. Ges. Ingenieurbiol., 3: (1988) 50-77.

2. S.B.Mickovski, Resilient design of landslip prevention measures: a case study. Proceedings of the ICE - Forensic Engineering 09/2014; DOI: 10.1680/feng.14.00001 (2014).

3. N.J.Copin, I.J.Richards, Use of Vegetation in Civil Engineering. CIRIA, Butterworths, London (1990)

4. D.H.Gray, R.B.Sotir, Biotechnical and eco-engineering slope stabilization. Wiley, New York, (1996) p. 276.

5. A.Stokes, G.Douglas, T.Fourcaud, F.Giadrossich, C.Gillies, T.Hubble, et al., Ecological mitigation of hillslope instability: ten key issues facing researchers and practitioners. Plant Soil, (2014) 377:1-23.

6. D.Gray, A.Leiser, Biotechnical slope protection and erosion control. Melbourne, fl, Kreiger Publishing Co. (1982) p.288.

7. B.Heed, Gully development and control. The status of our knowledgement: Research paper RM 19. Fort Collins, CO. U.S. Department of Agriculture, Forest Service. Rocky Mountains Forest and Range Experiment Station. (1976) p. 42.

8. G.Keller, J.Sherar, Guide for Best Management Practices for Rural Trails. USDA, Forest Service. Plumas National Forest, California (2001).

9. R.López Alonso, A.Pérez Gispert, R.I.Batalla, Efectos de un incendio forestal sobre la respuesta hidrológica de la cuenca mediterránea de Arbúcies. Investigación agraria: sistemas y recursos forestales 13(2), (2004) 305-316.

10. V.T.Chow, D.R.Maidment, L.W.Mays, Applied Hydrology. McGraw Hill. (1988) p. 572.

\section{References}

11. F.López Cadenas De Llano (Dir.) et al., Restauración Hidrológico Forestal de Cuencas y Control de la Erosión. Ingeniería Medioambiental ( $2^{\mathrm{a}}$ Ed.). Ministerio de Medio Ambiente. Tragsa. Tragsatec (1998).

12. F.Arriaga Martitegui, R.Argüelles Álvarez, $2^{\circ}$ Ed. $1^{\mathrm{a}}$ imp., Cálculo de estructuras de madera. Diseño y cálculo. Asociación de Investigación Técnica de las Industrias de la Madera. AITIM (2000) 